\title{
Improving Performance through Vertical Disintegration: Evidence from UK Manufacturing Firms
}

\author{
Panos Desyllas* \\ University of Manchester, Manchester Business School, Manchester, UK
}

\begin{abstract}
Unlike previous work on the vertical integration-performance relationship, we investigate the performance consequences of vertical disintegration. We offer a theoretical justification for the disintegration decision and we condition the disintegration effect on performance on the initial degree of firm integration, the timing and the direction of disintegration. Using a sample of UK manufacturing firms and controlling for disintegration endogeneity, we find that disintegration eventually results in improved operating performance, particularly when disintegration occurs as a reaction to poor performance and in cases of forward between-sector disintegration. However, being highly integrated does not guarantee gains from disintegration. The implications of these findings are discussed. Copyright $(\mathbb{C} 2008$ John Wiley \& Sons, Ltd.
\end{abstract}

\section{INTRODUCTION}

There is a widespread trend for firms to move away from integrated production and towards cooperative relations among independent organizations (Robins, 1993; D'Aveni and Ravenscraft, 1994; Gilley and Rasheed, 2000). Vertical disintegration has affected even firms whose vertical control over their value chains had historically constituted an important basis for their competitive advantage, such as Alcoa, Lucent and General Motors (Christensen et al., 2002; Sako, 2005; Engardio et al., 2006). In response to this trend, this paper asks whether and under what conditions those firms that reduce their vertical scope succeed in improving their subsequent operating performance.

Following Coase's (1937) seminal contribution, there have been two streams of work on the

\footnotetext{
*Correspondence to: University of Manchester, Manchester Business School, Manchester, UK.

E-mail: pdesyllas@gmail.com
}

relationship between organizational choice and performance, which are most relevant to our research questions. The first stream examines whether firms whose organizational choices are aligned with the prescriptions of transaction cost theory (Williamson, 1975, 1979, 1981) economize on transaction costs, which in turn should translate into better performance. There is agreement among scholars that choosing an organizational form in response to transaction hazards increases performance (Masten, 1993; Mayer and Nickerson, 2005; Geyskens et al., 2006-a meta-analysis of 200 studies). The second stream is concerned with the relationship between vertical integration and performance across firms. Here, the evidence is less clear cut. D'Aveni and Ravenscraft (1994) found that, although vertically integrated lines of business economize on general, administrative, selling, advertising and R\&D expenditures, they have higher production costs and thus achieve only marginally better profitability. Turning to evidence from firm-level data, Gilley and Rasheed (2000) found that there

Copyright (C) 2008 John Wiley \& Sons, Ltd. 
was no significant relationship between the level of vertical integration (their independent variable is outsourcing-intensity) and the overall financial performance of their sample firms. A neutral relationship between vertical integration and performance was also found by Peyrefitte and Golden (2004), but only with respect to vertical integration between different stages of the value chain. Contrary to their hypothesis, they found that vertical integration within a single stage of the value chain is negatively related to performance. More recent evidence presented by Rothaermel et al. (2006) suggests that excessive emphasis on vertical integration or outsourcing is detrimental to new product introductions, product success and sales.

Unlike these studies, we take the disintegrating firm as the unit of our analysis and we conceptualize vertical disintegration as an attempt by managers to improve their performance by reducing the vertical scope of the firm. To the best of our knowledge, the relationship between vertical disintegration and performance has been addressed only in Robins' (1993) case study of Warner Brothers' film-making activity during the period 1946-65. Robins found that the change in Warner Brothers' structure from fully integrated production and distribution to a more complex system of contracting with independent producers did, in fact, lead to improved performance.

Our objective is to investigate whether firms that disintegrate improve their operating performance and to develop and test predictions about the conditions under which disintegration is more likely to enhance performance. We expect that a firm that becomes less integrated will benefit by focusing its limited resources on its core operations (Prahalad and Hamel, 1990; Quinn and Hilmer, 1994), by tapping into unique outside resources and capabilities (Quinn and Hilmer, 1994), by alleviating production and coordination costs arising from high vertical integration (Markides, 1995; Daley et al., 1997; Harrigan, 1985; Mahoney, 1992) and by achieving greater strategic flexibility enabling it to respond to changing competitive conditions (e.g. Hitt et al., 1998; Shimizu and Hitt, 2004). We condition the disintegration effect on three factors. First, we distinguish between initially highly integrated firms that disintegrate and other disintegrating firms. We hypothesize that the performance gains upon disintegration will be relatively larger for the initially highly integrated disintegrating firms. Second, we distinguish between reactive and proactive disintegration, depending on whether the performance of the disintegrating firm is inferior - as opposed to being at least comparable - to its competitors' performance. We hypothesize that performance improvements will be relatively larger and will be subject to less uncertainty when firms reorganize their vertical boundaries in response to poor performance. Third, we distinguish between between-sector disintegration, which occurs when manufacturing firms exit from operations in raw materials or services, and within-manufacturing disintegration. We hypothesize that the benefits from disintegration will be relatively larger for between-sector disintegration.

There are two additional novel elements in our approach. First, we construct a discrete proxy for disintegration by focusing on firms that reduced their degree of vertical integration through divestitures of business segments that were previously vertically related to the parent firm. Using identifiable events to construct our proxy for vertical disintegration facilitates the examination of the performance consequences of disintegration by excluding firms that undergo slow or marginal changes in the sourcing mode of activities and which are likely to have an immaterial effect on performance. Second, we utilize recent econometric developments about causal inference in the estimation of the disintegration effect on performance. As has been stressed in the literature (Bowman et al., 1999; Mayer and Nickerson, 2005), the challenge for empirical work on organizational restructuring is to develop estimation methods for comparing a company's performance after restructuring against its counterfactual performance. We adopt a novel method of matching sample with control firms in the estimation of counterfactual performance, i.e. the propensity score matching method (Rosenbaum and Rubin, 1983, 1984, 1985), which corrects for possible endogeneity of strategic decisions to firms' own characteristics.

The remainder of this paper is organized as follows. The next section develops the theoretical background for the study and the specific hypotheses. This is followed by a section describing the data and the methodology employed. Then, the empirical results of the analysis are presented. The final section discusses the findings of this study and draws out their 
implications for a better understanding of vertical disintegration strategies.

\section{THEORY AND HYPOTHESES}

The decision about which of the operations of the value-added chain should be carried out internally and which ones should be outsourced is an important decision that managers need to make. Two of the most widely employed theoretical frameworks for the analysis of governance arrangements offer different normative rules. According to transaction cost economics, transactions should take place within the institutional framework-market or hierarchywhich allows them to be executed most efficiently (Williamson, 1975, 1979, 1981). Specifically, transactions should be internalized when they are characterized by a high degree of human or physical asset specificity, demand uncertainty and transaction frequency. In such cases, market failures make the writing and enforcement of contracts excessively costly or even impossible. The emergence of the resource-based view of the firm (Wernerfelt, 1984; Dierickx and Cool, 1989; Barney, 1991) has shifted, to some extent, the emphasis on the debate from cost-efficiency considerations at the transaction level to strategic considerations at the firm level. Scholars have argued that firms should internally perform operations that are directly related to or which leverage a firm's core competences (Prahalad and Hamel, 1990), which apply resources that are complementary to a firm's valuable productive capabilities (Leiblein, 2003; Teece, 1993) or that enable the firm to create, combine and transfer knowledge resources more effectively, relative to the markets (Kogut and Zander, 1992).

However, governance choices need to be seen in the light of the dynamic nature of a firm's internal and external environments. On the one hand, various market parameters that affect the potential for, and the transaction costs of, external sourcing are constantly changing. The opportunities to reorganize the boundaries of firms change as industries evolve, firms specialize and the roster of qualified potential partners changes (Jacobides, 2005; Jacobides and Winter, 2005). In addition, the transaction costs of external sourcing have been altered considerably by the rapid advances in information and communication technologies (ICT) (Brynjolfsson et al., 1994; Abramovsky and Griffith, 2006), and the globalization of markets in finances, goods, services and labour (e.g. Jones, 2002). On the other hand, a firm's resource base is subject to constant change with the development of new resources and capabilities through investment and learning and due to the depreciation and amortization of existing resources (Eisenhardt and Martin, 2000; Helfat and Peteraf, 2003). As a result, firms may need to revisit their chosen governance modes in order to optimize and realign them with the changing environments.

\section{The Causal Effect of Disintegration on Performance}

We conceptualize vertical disintegration as an attempt by managers to enhance future performance by reducing the vertical scope of their firm. Various arguments grounded on the management literature justify the decision to disintegrate as a means of improving the overall efficiency and effectiveness of the firm. By divesting non-core operations and reallocating the related tasks from within the organizational unit to suppliers, the firm can focus its resources on its core operations. As the firm becomes more focused, it can enhance the competencies that support its core operations more effectively than its competitors (Prahalad and Hamel, 1990; Bettis et al., 1992; Quinn and Hilmer, 1994), while it will be less likely to suffer from the inefficiencies that often arise from managing strategically dissimilar non-core businesses (Prahalad and Bettis, 1986). A less integrated firm can reap additional benefits from developing partnerships with other 'best-in-their-class' firms. In this way, the firm can complement its resources (Harrigan, 1984; Quinn and Hilmer, 1994), learn from suppliers/ distributors and upgrade its own capabilities (Sorenson, 2003; Quinn and Hilmer, 1994) and explore emerging technologies without bearing internally the associated risks (Quinn, 1992, 2000; Leiblein, 2003). By becoming leaner and more embedded in its environment, the firm can also improve its strategic flexibility (Hitt et al., 1998; Shimizu and Hitt, 2004). As a result, it will be better positioned to identify major changes in the external environment and to quickly commit resources to new courses of action or reverse 
existing resource commitments in response to those changes.

Another group of arguments that are rooted in economic principles suggest that firms can benefit from disintegration by avoiding what can be broadly termed the 'costs of vertical integration'. We employ this term to summarize the production, and agency and coordination costs that may escalate when a firm undertakes a large number of operations. Savings in production costs can be achieved by eliminating diseconomies of scope that often emerge when a large number of tasks are pursued simultaneously (Penrose, 1959; Markides, 1995), avoiding negative externalities that are often imposed across certain combinations of operations (Stigler, 1951; John and Ofek, 1995; Daley et al., 1997) or by eliminating underutilized productive capacity due to differences between upstream and downstream operations (Harrigan, 1985; Mahoney, 1992). Additional savings can be achieved when vertically integrated supplier units, which are well insulated from competitive pressures, are replaced by relatively more efficient independent suppliers (Mahoney, 1992; D’Aveni and Ravenscraft, 1994). Savings in agency and coordination costs can be achieved by reducing the bureaucratic complexity of the firm. In a less integrated and organizationally simpler firm, information flows across the organization are improved and problems of information deficits due to information asymmetries become less common (Hitt et al., 1996). As a result, performance monitoring and coordination become less problematic (D'Aveni and Ilinitch, 1992; Mahoney, 1992). On the basis of the above arguments, we can state our first hypothesis:

\section{Hypothesis 1:}

Firms that disintegrate will experience an improved operating performance relative to their estimated counterfactual performance.

\section{The Degree of Vertical Integration of the Disintegrating Firm}

As we discussed earlier, an important way in which changes in the macro environment can trigger changes in organizational governance is by affecting the transaction costs faced by firms. In particular, the recent advances in ICT and the trend towards the globalization of markets have been identified as key drivers of the observed disintegration and outsourcing activity (Brynjolfsson et al., 1994; Jones, 2002; Hitt et al., 1998). As the transaction costs are decreasing, there will be a number of firms that, although they found it unprofitable to outsource before, can now take advantage of external sourcing on more favourable terms. To the extent that the hypothesized managerial and economic costs of vertical integration are proportional to the initial degree of integration of a firm, the relatively highly integrated firms should be the first to take advantage of transaction cost reductions. That is, at a given point in time, the most integrated firms in an industry will experience greater benefits from reducing their vertical scope compared with the rest of the firms in the same industry who disintegrate. Outsourcing intensity may itself be subject to diminishing returns. Highly disintegrated firms may have almost exhausted their potential for performance improvement through disintegration, as they are likely to have already outsourced those operations for which external sourcing is expected to generate the highest performance benefits. In addition, highly disintegrated firms may face escalating costs of managing multiple partnerships and they may suffer from a deteriorated absorptive capacity to internalize knowledge from suppliers (Rothaermel et al., 2006). Therefore, we hypothesize that

\section{Hypothesis 2:}

The initially highly integrated firms that disintegrate will experience a larger improvement in operating performance compared with other disintegrating firms.

\section{The Timing of Disintegration}

As in similar work on organizational restructuring (Cameron et al., 1993; Lee, 1997; Love and Nohria, 2005), we distinguish between 'reactive' and 'proactive' disintegration on the basis of the disintegrating firm's operating performance relative to its competitors. Accordingly, a firm disintegrates reactively (proactively) when its operating performance is inferior to (at least comparable to) that of its industry counterparts.

This distinction implies that reactive disintegration is implemented as a defensive reaction to poor performance with the objective of catching up with its competitors. Poor performance can be the result of a widening misalignment between the firm and its environment. As firms become older and larger, they become increasingly unresponsive to changes in 
demand, supply and competitive conditions, due to structural inertia, and eventually they may lack consistency with changing environments (Hannan and Freeman, 1984; Johnson, 1990). In fact, an inappropriate alignment of organizational form with transaction hazards has been identified as a key cause of underperformance (Masten, 1993; Mayer and Nickerson, 2005). On the contrary, proactive disintegration is implemented as a strategy, which aims at further improving efficiency, enhancing revenues and bolstering competitiveness by taking advantage of perceived emerging opportunities. Eisenhardt and Brown (1999) use the term 'patching' to describe the process by which managers routinely remap businesses to changing market opportunities. In this perspective, proactive disintegration becomes part of the organizational routines and converges on the concept of dynamic capabilities (Teece et al., 1997; Eisenhardt and Martin, 2000).

We predict that the effect on performance of reactive disintegration will be relatively larger and subject to less uncertainty compared with the effect of proactive disintegration, at least when the effect on performance is measured in the medium term (about 3 years after disintegration). On the one hand, in reactive disintegration the managers of poorly performing firms are relatively better positioned to overcome internal resistance to change by using poor performance to legitimate changes that might be politically difficult otherwise (Finkelstein and Hambrick, 1996). On the other hand, it may be relatively easier for underperforming firms to catch up with their industry brethren by simply imitating what constitutes a 'standard' industry practice. For instance, a poorly performing firm in the microcomputer industry, which is backward vertically integrated - designing and producing its own chips - could benefit by outsourcing chip design and production to Intel - which dominates the global microprocessor market - and focusing on other activities of the value chain (Rothaermel et al., 2006). In contrast, proactive disintegration is likely to be subject to greater uncertainty, as it tends to involve extended experimentation. As Hamel and Prahalad (1994) argue, developing an independent point of view on tomorrow's opportunities and how to exploit them is more challenging than simply benchmarking a competitor's offerings and imitating its methods. Therefore, we state our third hypothesis

\section{Hypothesis 3:}

Firms that disintegrate reactively will experience an improvement in their operating performance, which is larger (3a), and subject to lower uncertainty (3b) compared with the performance effect that is experienced by firms that disintegrate proactively.

\section{The Direction of Disintegration}

The performance consequences of disintegration may depend on the direction of disintegration with reference to the centre of gravity of the firm (Galbraith, 1983). It has been suggested that, because a firm's centre of gravity represents the stage of the value-added chain where the firm's operations began and where lessons were learned, the firm's ability to carry out operations that are fundamentally different from its centre of gravity will be impaired. In order to account for this possibility, we distinguish between disintegration that takes place between sectors and disintegration that occurs within a given sector (Davis and Duhaime, 1992; Peyrefitte and Golden, 2004). Between-sector disintegration for manufacturing firms (e.g. a firm that operates in SIC 29: Petroleum refining and related industries) involves exiting either from operations belonging to an upstream sector (e.g. SIC 13: Oil and gas extraction) or from operations belonging to a downstream sector (e.g. SIC 55: Automotive dealers and gasoline service stations). Withinmanufacturing disintegration involves exiting from operations where the output from the operation abandoned (e.g. 2911: Petroleum refining) constitutes an input for the continuing manufacturing operations (e.g. 2992: Lubricating oils and greases).

We suggest that performance gains will be larger when a firm becomes less integrated by exiting from upstream or downstream sectors of the value-added chain relative to withinmanufacturing disintegration. This is because reductions in between-sector integration allow exiting from operations, which are far beyond the centre of gravity of the firm and where it may not possess the necessary competences for success. On the basis of the above arguments, we can state our final hypothesis

\section{Hypothesis 4:}

Backward between-sector disintegration (4a), and forward between-sector disintegration (4b) will 
lead to a larger improvement in operating performance relative to within-manufacturing disintegration.

\section{METHODS}

\section{Sample}

The analysis is conducted on the basis of a data set that includes 764 publicly traded manufacturing (SIC 20-39) UK firms that are listed in the Datastream database for some part of the sample period and which satisfy data requirements. As we will explain in detail, vertical disintegration is proxied by divestitures of business segments that were previously vertically related to the parent firm. The sample of divestitures is drawn from the Thomson One Banker electronic database. A divestiture is a deal where the parent company is losing majority control over the divested segment of the company. The divested segment may consist of assets, product lines or subsidiaries. From the total of 764 sample firms, 350 firms made a total of 2134 divestitures during the period from 1993 to 2003. Because in some years a given firm divests more than one unit, and as their effects cannot be disentangled using annual accounting data, their aggregate effect on the parent firm's subsequent performance is examined. This leads to a total of 986 aggregated divestiture events, of which 466 divestiture events are classified as vertical.

\section{Estimating the Counterfactual Performance}

The problem that arises in estimating the causal effect of disintegration on performance is that it is impossible to observe what the performance would have been had the disintegration not occurred. Various matching techniques have been developed to estimate the counterfactual performance, by utilizing information from nondisintegrating firms, against which the observed performance can be judged. However, the assignment of firms to the categories of disintegrating and non-disintegrating may not be random, but may be endogenous to certain firm characteristics. A matching methodology can only yield an unbiased estimate of the causal effect if the two groups of firms are as similar as possible. Usually, sample and control firms are matched on the basis of industry and size or prior performance (John and Ofek, 1995; Barber and Lyon, 1996; Cho and Cohen, 1997; Atiase et al., 2004; Denis and Shome, 2005). However, if there are additional variables of relevance in the matching process, there is a need to determine which ones should be dropped as otherwise, the matching process becomes highly complicated.

To address this problem we will employ a novel matching technique, the so-called propensity score matching (Rosenbaum and Rubin, 1983, 1984, 1985). This is effectively a multivariate matching methodology that, however, reduces the dimensions of conditioning by matching the sample to control firms on the basis of a monodimensional propensity score that summarizes the pre-event characteristics of the sample and control units. In this way, this matching method corrects for the possible endogeneity of strategic decisions to firms' own characteristics and for the management's expectation of performance outcomes with respect to the strategy chosen (Hamilton and Nickerson, 2003; Villalonga, 2004; Danzon et al., 2007).

For the construction of the counterfactual performance, the following algorithm is employed (see Sianesi, 2001). First, the likelihood of disintegration (i.e. vertical divestiture) is estimated as a function of firm characteristics using logistic regression analysis. The estimated probability of disintegration is the propensity score. Second, each disintegrating firm is matched to the three non-disintegrating firms with the closest propensity score. The nondisintegrating firms are drawn with replacement from the population of all the firms operating in the same industry that are not active in any divestiture during the 4-year period starting at the last pre-disintegration year and lasting throughout the period over which the disintegration effect is examined. Because often for some disintegrating firms there are no comparable non-disintegrating firms, some bias might remain even after matching. Therefore, we will check the robustness of our estimates from the full sample for a subset of cases satisfying the 'common support' condition. This means that disintegrating firms whose propensity score is larger than the largest propensity score of non-disintegrating firms operating in the same industry are excluded from the analysis. 


\section{Dependent Variable}

Our aim is to estimate the causal effect of vertical disintegration on operating performance. Operating performance is proxied by the return on capital employed (ROCE) and it is measured by the ratio of operating profit to total assets minus current liabilities. We choose this proxy of operating performance over alternative performance indicators (e.g. the return on sales is frequently employed) for two main reasons. First, the return on capital provides a better yardstick than alternative indicators of shareholders' wellbeing in a context in which managers are assumed to restructure operations in the shareholders' interests (Haynes et al., 2002). Second, using this proxy ensures consistency with other UK studies on divestiture and performance (e.g. Haynes et al., 2002, 2003).

Because the decision to disintegrate may also be influenced by unobservable factors that differ systematically between disintegrating and nondisintegrating firms, we employ the difference-indifference estimator that allows for time-invariant unobservable differences between the two groups of firms (Todd, 1999). Thus, our dependent variable is the Change in Control-adjusted Operating Performance and it is estimated as follows:

$$
\begin{aligned}
\Delta \text { COPERF }_{i, t+j}= & \left(O P E R F_{i, t+j}-O P E R F_{i, t}\right) \\
& -\left(O P E R F_{c, t+j}-O P E R F_{c, t}\right)
\end{aligned}
$$

Thus, the change in control-adjusted operating performance for firm $i$ between $j$ years after disintegration and the disintegration year $t$ equals the change in firm $i$ 's operating performance minus the change in the average operating performance of the three matched control firms to firm $i$ over the same period. As in previous studies (e.g. John and Ofek, 1995; Denis and Shome, 2005), the period over which the disintegration impact on performance is examined is a maximum of 3 years. Although we would like to extend the estimation period over a longer period, there are two practical reasons that limit our discretion. First, extending this period increases the danger that significant confounding factors will affect the estimated effect. Second, as we move away from the disintegration year, there is a significant loss in the number of firms with observations on performance (about 16\% per year). Therefore, it becomes difficult to assess whether the estimated disintegration effects should be attributed to actual trends or whether they are an artefact of the data.

Following the practice of studies of divestitures (John and Ofek, 1995; Atiase et al., 2004; Denis and Shome, 2005), we measure the change in performance of a firm's remaining assets following disintegration. We are able to construct this measure as, in the disintegration year, the firm's operating performance does not include the results of the divested segments. We focus on the operating performance of the continuing operations as this is the entity that is affected by the decision to disintegrate. Thus, the estimated effect on performance is not affected by whether the performance of the divested segment was better or worse than that of the parent company.

\section{Independent Variables}

Vertical Disintegration is proxied using divestitures of business segments that were previously vertically related to the parent firm. In order to establish a vertical relationship, we focus on divestitures that lead to a fall in the industryadjusted value-added to sales ratio during the first post-divestiture year relative to the last predivestiture year. We use deviations from industry median values to control for industry and year effects, given the evidence that vertical integration is both time and industry dependent (e.g. Stigler, 1951; Mitchell and Mulherin, 1996; Jacobides, 2005). From the definition of value-added, as the difference between revenues and the cost of bought-in materials, components and services, ${ }^{1}$ it follows that a fall in the value-added to sales ratio implies that the share of the costs of bought-in materials, components and services rises relative to sales. We find that our sample includes 466 events involving 1045 divestitures that lead to a fall in the industry-adjusted value-added to sales ratio, which are thus classified as 'vertical'. The transaction value of 721 vertical divestitures with disclosed value totals $£ 66.7$ billion (2001 prices). The value of the assets divested per vertical event accounts, on average, for about $12 \%$ of the parent's total assets.

A possible limitation of our proxy for vertical disintegration is that sometimes firms might choose to disintegrate through layoffs or by closing down plants. However, lacking this information is unlikely to be of great importance 
as, in a similar context, Denis and Shome (2005) find that the majority of their sample firms that aimed at reducing their scope did so through asset sales. An advantage of our discrete proxy for disintegration is that, by excluding firms that undergo slow or marginal changes in the sourcing mode of activities and which are likely to have an immaterial effect on performance, we are better able to examine the consequences of disintegration. This is important, given the evidence on the sensitivity of the profitability-vertical integration relationship to the specification of vertical integration adopted (Maddigan and Zaima, 1985).

The disintegration effect on performance is conditioned on the initial degree of integration of the disintegrating firm, the timing and the direction of disintegration. We employ an indicator for Highly integrated disintegrating firms vs Other disintegrating firms that splits the sample into two groups, depending on whether the pre-event level of industry-adjusted vertical integration of a disintegrating firm is above the median value of industry-adjusted vertical integration across all the disintegrating firms in our sample. We employ an indicator for Reactive disintegration vs Proactive disintegration that splits the sample into two groups, depending on whether disintegration takes place when the operating performance of a disintegrating firm is below, or at or above the industry median in the last preevent year. Finally, we employ an indicator for Backward between-sector vs Forward betweensector vs Within-manufacturing disintegration by utilizing information on the industrial classification of the divested segment and the disintegrating firm (See Davis and Duhaime, 1992). As all the disintegrating firms are manufacturing firms (SIC 20-39), when the SIC code of the divested unit belongs to raw materials (SIC 01-19), the deal is classified as backward disintegration. When the SIC code of the divested unit belongs to services (SIC 40-99), the deal is classified as forward disintegration. When both the divested unit and the disintegrating firm belong to manufacturing, the deal is classified as withinmanufacturing disintegration.

\section{The Propensity Score Matching}

Using a multinomial logit regression we estimate the propensity score. The dependent variable takes on three different values, depending on whether a firm has no divestiture activity, it is active in vertical divestitures or it is active in non-vertical divestitures in a given year. With vertical divestitures being employed as a proxy for vertical disintegration, non-vertical divestitures can be thought of as downscoping or downsizing. We control for non-vertical divestitures in the analysis, as often a given firm is active in both types of divestiture activities during the period covered by our data set.

The regressors that are employed are 1-year lagged values of the following variables. Vertical integration is proxied by the value-added to sales ratio and it is measured as described above. It is employed to control for the larger potential of more integrated firms to reduce their vertical scope. Operating performance is proxied by the ROCE as described above, and operating performance growth is measured by the annual growth of operating performance. We account for the level and change in performance because poor performance has been identified as a catalyst for restructuring (John and Ofek, 1995; Lang et al., 1995; Markides, 1995; Cho and Cohen, 1997; Haynes et al., 2003; Denis and Shome, 2005). In accordance with earlier work, we also control for Size (the natural logarithm of the number of employees), Age (the natural logarithm of the number of years since incorporation), Leverage (the ratio of total debt to the book value of equity), an Acquisition Dummy (equal to unity when a firm acquires another company), Industry Sales Shock (the difference between the sales growth in that industry and the average sales growth across all manufacturing industries in the same year), as well as industry and year dummies.

The results from the regression analysis are presented in Table 1. The likelihood of vertical disintegration is not significantly related to operating performance or operating performance growth, but it is significantly positively related to the level of a firm's vertical integration. With respect to the rest of the regressors, we find that the disintegration likelihood is significantly positively related to the size and age of firms, to their leverage and to their having carried out an acquisition in the previous year. A crucial implication of these results is that the firms that disintegrate through divestiture are indeed not a random sample of firms, but they have particular characteristics. Therefore, an unbiased estimate of 


\section{Table 1. Multinomial Logit Regression for Estimating the Divestiture Probability, Regression} Coefficients

\begin{tabular}{|c|c|c|c|}
\hline Regressor & Vertical divestitures $_{t}$ & & Non-vertical divestitures $_{t}$ \\
\hline Vertical integration $_{t-1}$ & $\begin{array}{l}0.069^{* * *} \\
(0.016)\end{array}$ & & $\begin{array}{l}-0.009^{* * * *} \\
(0.002)\end{array}$ \\
\hline Op. performance ${ }_{t-1}$ & $\begin{array}{c}-0.012 \\
(0.011)\end{array}$ & & $\begin{array}{l}-0.061^{* * *} \\
(0.013)\end{array}$ \\
\hline Op. performance growth ${ }_{t-1}$ & $\begin{array}{c}-0.002 \\
(0.001)\end{array}$ & & $\begin{array}{l}-0.004^{* *} \\
(0.002)\end{array}$ \\
\hline $\operatorname{Size}_{t-1}$ & $\begin{array}{l}0.025^{* * *} \\
(0.003)\end{array}$ & & $\begin{array}{l}0.044^{* * * *} \\
(0.004)\end{array}$ \\
\hline $\mathrm{Age}_{t-1}$ & $\begin{array}{l}0.010^{* * *} \\
(0.004)\end{array}$ & & $\begin{array}{l}0.017^{* * *} \\
(0.006)\end{array}$ \\
\hline Leverage $_{t-1}$ & $\begin{array}{r}0.004^{*} \\
(0.002)\end{array}$ & & $\begin{array}{l}0.012^{* * *} \\
(0.003)\end{array}$ \\
\hline Acquisition dummy ${ }_{t-1}$ & $\begin{array}{l}0.026^{* * *} \\
(0.006)\end{array}$ & & $\begin{array}{l}0.038^{* * *} \\
(0.010)\end{array}$ \\
\hline Industry sales shock ${ }_{t-1}$ & $\begin{array}{c}0.009 \\
(0.016)\end{array}$ & & $\begin{array}{r}-0.014 \\
(0.022)\end{array}$ \\
\hline Intercept & $\begin{array}{l}-0.363^{* * *} \\
(0.033)\end{array}$ & & $\begin{array}{l}-0.627^{* * *} \\
(0.043)\end{array}$ \\
\hline Industry dummies (LR test) & \multicolumn{3}{|c|}{$62.73^{* * *}$} \\
\hline $\begin{array}{l}\text { Year dummies (LR test) } \\
\text { No. of observations }\end{array}$ & \multicolumn{3}{|c|}{$51.16^{* * *}$} \\
\hline No. of firms & \multicolumn{3}{|c|}{764} \\
\hline No. of divestitures (vertical) & \multicolumn{3}{|c|}{$2,134(1,045)$} \\
\hline No. of events (vertical) & \multicolumn{3}{|c|}{$986(466)$} \\
\hline Log likelihood & \multicolumn{3}{|c|}{$-2,500.6$} \\
\hline Chi-squared & \multicolumn{3}{|c|}{$578.0^{* * *}$} \\
\hline Pseudo R-squared & \multicolumn{3}{|c|}{0.18} \\
\hline
\end{tabular}

The dependent variable takes on three different values, depending on whether a firm has no divestiture activity, it is active in vertical divestitures, or it is active in non-vertical divestitures. Estimated coefficients are reported in terms of marginal effects evaluated at the averages of the regressors. Robust standard errors to within-firm serial correlation are reported in parentheses. The base industry is SIC 20 and the base year is 2003 . ${ }^{* * *} p<0.01 ;{ }^{* *} p<0.05 ;{ }^{*} p<0.1$.

the effect of vertical disintegration on performance can only be obtained if these heterogeneities are accounted for, as the propensity score matching does.

In the analysis that follows, the results on the disintegration effects are reported for all the 464 disintegrating firms, ${ }^{2}$ as well as for the 318 disintegrating firms that satisfy the common support condition. With the imposition of the common support condition, the mean difference in propensity scores between sample firms and their matched controls falls, from 0.12 when all 464 sample firms are considered, to just 0.04 . The balancing of the covariates between the sample and control firms after the propensity score matching can be assessed in Table 2, which reports the mean values and the difference in mean values of the covariates for the sample firms and the average of their matched controls. The matching process has eliminated most of the differences in the covariates that have been accounted for in our regression between the sample firms and non-disintegrating firms that serve as controls. Both the variables that are central to our analysis, vertical integration and operating performance, are well balanced after the matching. Although the matching has eliminated the large size discrepancy between sample and control firms, some discrepancy remains after the matching. This is due to the fact that in some industries there are only a few firms that can serve as controls, some of which are not comparable to the sample firms in terms of size. The effect of any remaining observable or unobservable differences between sample and matched control firms should be minimized by employing the difference-indifference estimator.

\section{RESULTS}

Tables 3 and 4 report the mean and median estimated effects on operating performance-and 
Table 2. Covariate Means Before and After Propensity Score Matching

\begin{tabular}{|c|c|c|c|c|c|c|c|c|c|}
\hline \multirow[t]{2}{*}{ Variable } & \multicolumn{3}{|c|}{ Before matching } & \multicolumn{3}{|c|}{$\begin{array}{l}\text { After matching } \\
\text { All vertical divestiture } \\
\text { events }\end{array}$} & \multicolumn{3}{|c|}{$\begin{array}{l}\text { After matching } \\
\text { Vertical divestiture events with } \\
\text { 'common support' condition }\end{array}$} \\
\hline & $\begin{array}{l}(1) \\
\text { Sample } \\
\text { firms }\end{array}$ & $\begin{array}{l}(2) \\
\text { Potential } \\
\text { controls }\end{array}$ & $\begin{array}{l}(3)= \\
(1)-(2)\end{array}$ & $\begin{array}{l}(4) \\
\text { Sample } \\
\text { firms }\end{array}$ & $\begin{array}{l}(5) \\
\text { Matched } \\
\text { controls }\end{array}$ & $\begin{array}{l}(6)= \\
(4)-(5)\end{array}$ & $\begin{array}{l}(7) \\
\text { Sample } \\
\text { firms }\end{array}$ & $\begin{array}{l}(8) \\
\text { Matched } \\
\text { controls }\end{array}$ & $\begin{array}{l}(9)= \\
(7)-(8)\end{array}$ \\
\hline No. of observations & 464 & 2,431 & & 464 & 1,392 & & 318 & 954 & \\
\hline Op. performance $e_{t-1}$ & 0.146 & 0.084 & 0.034 & 0.146 & 0.142 & 0.004 & 0.146 & 0.147 & -0.001 \\
\hline Vertical integration $_{t-1}$ & 0.391 & 0.124 & 0.223 & 0.391 & 0.388 & 0.003 & 0.377 & 0.385 & -0.008 \\
\hline Size $_{t-1}$ & 8.329 & 6.394 & 1.698 & 8.329 & 7.435 & 0.893 & 7.651 & 7.287 & 0.364 \\
\hline $\mathrm{Age}_{t-1}$ & 3.794 & 3.300 & 0.407 & 3.794 & 3.616 & 0.178 & 3.633 & 3.616 & 0.017 \\
\hline Op. performance growth ${ }_{t-1}$ & -0.310 & -0.131 & -0.156 & -0.310 & -0.329 & 0.018 & -0.262 & -0.386 & 0.124 \\
\hline Leverage $_{t-1}$ & 0.592 & 0.387 & 0.169 & 0.592 & 0.493 & 0.098 & 0.462 & 0.494 & -0.032 \\
\hline Acquisition dummy $_{t-1}$ & 0.526 & 0.211 & 0.252 & 0.526 & 0.311 & 0.215 & 0.441 & 0.294 & 0.147 \\
\hline
\end{tabular}

Each sample firm is matched to three non-disintegrating firms with the closest propensity score. The latter are drawn with replacement from the population of all firms operating in the sample firm's industry that are not active in divestitures during the 4-year period starting at the last pre-disintegration year. The 'common support' condition means that disintegrating firms whose propensity score is larger than the largest propensity score of non-disintegrating firms operating in the same industry are excluded from the analysis.

the proportion of positive effects across disintegrating firms - for each of the three postdisintegration years. We primarily focus our attention on the median effect because the distribution of the estimated effect is skewed and there are some extreme observations. Table 3 tabulates the effect for all the disintegrating firms, whereas Table 4 includes only those firms that satisfy the common support condition. Statistical significance is assessed using the $t$-test with bootstrapped standard errors, the Wilcoxon signed-rank test and the Sign test.

We begin by examining the overall disintegration effect on performance. According to Hypothesis 1, the disintegrating firms will experience an improved performance relative to their estimated performance had they not disintegrated. However, the results in the two tables suggest that in the first post-disintegration year disintegrating firms do worse (in terms of medians) than or at best as well (in terms of means and per cent positive effects) as their matched counterparts. We suspect that the performance deterioration reflects various disintegrationrelated costs incurred. ${ }^{3}$ Unfortunately, we cannot provide evidence on the actual magnitude of restructuring costs, because Datastream does not provide the required accounting information for the sample firms. Interestingly, the results suggest that this negative effect is a rather temporary phenomenon. In the second and third post-disintegration years, the negative effect on performance is reversed, with the average and median effects on performance and the proportion of positive effects indicating a neutral or significantly positive effect. The results relating to the median disintegration effect of Table 4, where the common support condition is satisfied, suggest that though the disintegrating firms experience $4 \%$ lower performance in the first post-disintegration year, relative to the estimated counterfactual performance, ${ }^{4}$ performance recovers thereafter, becoming $8 \%$ higher in the second year and $22 \%$ higher in the third year than the estimated counterfactual performance. Three years after disintegration, a positive disintegration effect is estimated for some $58 \%$ of the cases. Therefore, we find support for Hypothesis 1, but only in the second and third post-disintegration years.

As a check of robustness, we tested whether the large differences in the estimated performance effect between the first and the next two postdisintegration years are due to the fall in the number of observations, but we found no evidence that this is the case. ${ }^{5}$ Another possibility is that our results might be sensitive to the extent of disintegration activity. To test this, we split the sample of disintegrating firms into those carrying out limited and those carrying out extended disintegration, depending on whether the industry-adjusted value-added to sales ratio fell by more than $50 \%$ relative to its 


\section{Table 3. The Effect of Vertical Disintegration on Operating Performance}

Test of Hypothesis 1. All disintegrating firms

\begin{tabular}{lrrcl}
\hline Period & Obs. & Mean & Median & $\%$ Positive \\
\hline $\mathrm{t}+1$ & 464 & -0.025 & $-0.004^{*}$ & 47.2 \\
$\mathrm{t}+2$ & 399 & 0.018 & 0.011 & $55.9^{* *}$ \\
$\mathrm{t}+3$ & 329 & 0.030 & $0.015^{* *}$ & 54.4 \\
\hline
\end{tabular}

Test of Hypothesis 2. The initial degree of vertical integration of the disintegration firms

(I) Highly-integrated disintegrating firms

\begin{tabular}{lccccccccc}
\cline { 2 - 4 } Period & Obs. & Mean & Median & \% Positive & & Obs. & Mean & Median & \% Positive \\
\hline $\mathrm{t}+1$ & 232 & $-0.041^{* *}$ & $-0.005^{*}$ & 45.7 & & 232 & -0.008 & -0.001 & 48.7 \\
$\mathrm{t}+2$ & 203 & -0.027 & 0.011 & $57.6^{* *}$ & & 196 & $0.066^{* *}$ & 0.013 & 54.1 \\
$\mathrm{t}+3$ & 167 & 0.013 & 0.002 & 51.5 & & 162 & 0.048 & $0.028^{* *}$ & $57.4^{*}$ \\
\hline
\end{tabular}

$p$-value for Mann-Whitney (I) v. (II): $t+1=0.40 ; t+2=0.32 ; t+3=0.27$.

Test of Hypothesis 3. Reactive versus proactive vertical disintegration

\begin{tabular}{|c|c|c|c|c|c|c|c|c|c|c|}
\hline \multirow[b]{2}{*}{ Period } & \multirow[b]{2}{*}{ Obs. } & \multicolumn{3}{|c|}{ (I) Reactive disintegration } & \multirow[b]{2}{*}{$\begin{array}{l}\text { Coef. of } \\
\text { Variation }\end{array}$} & \multirow[b]{2}{*}{ Obs. } & \multirow[b]{2}{*}{ Mean } & \multicolumn{3}{|c|}{ (II) Proactive disintegration } \\
\hline & & Mean & Median & $\%$ Positive & & & & Median & $\%$ Positive & $\begin{array}{l}\text { Coef. of } \\
\text { Variation }\end{array}$ \\
\hline$t+1$ & 187 & $-0.055^{* *}$ & -0.005 & 47.1 & 6.7 & 277 & -0.004 & -0.003 & 47.3 & 79.3 \\
\hline$t+2$ & 163 & 0.023 & $0.017^{* *}$ & $60.1^{* *}$ & 13.7 & 236 & 0.015 & 0.007 & 53.0 & 24.6 \\
\hline $\mathrm{t}+3$ & 134 & $0.043^{*}$ & $0.033^{* * *}$ & $61.2^{* *}$ & 6.5 & 195 & 0.022 & -0.001 & 49.7 & 20.1 \\
\hline
\end{tabular}

$p$-value for Mann-Whitney test (I) v. (II): $t+1=0.38 ; t+2=0.14 ; t+3=0.01$.

$p$-value for variance equality test (I) v. (II): $t+1=0.14 ; t+2=0.02 ; t+3=0.00$.

Test of Hypothesis 4. Between-sector versus within-manufacturing vertical disintegration

(I) Backward between-sector disintegration

\begin{tabular}{|c|c|c|c|c|c|c|c|c|}
\hline \multirow[b]{2}{*}{ Period } & & & & \\
\hline & Obs. & Mean & Median & $\%$ Positive & Obs. & Mean & Median & $\%$ Positive \\
\hline$\overline{t+1}$ & 34 & 0.010 & 0.009 & 55.9 & 186 & -0.007 & 0.002 & 50.5 \\
\hline$t+2$ & 31 & -0.002 & 0.026 & 54.8 & 160 & $0.061^{* *}$ & $0.015^{*}$ & $58.1^{* *}$ \\
\hline$t+3$ & 28 & 0.017 & 0.000 & 53.6 & 132 & $0.076^{* *}$ & $0.027^{* *}$ & $58.3^{* *}$ \\
\hline
\end{tabular}

(III) Within-manufacturing disintegration

\begin{tabular}{lcccl}
\cline { 2 - 5 } Period & Obs. & Mean & Median & $\%$ Positive \\
\hline $\mathrm{t}+1$ & 358 & $-0.033^{* *}$ & $-0.006^{* * *}$ & $44.7^{* *}$ \\
$\mathrm{t}+2$ & 309 & -0.004 & 0.008 & 53.4 \\
$\mathrm{t}+3$ & 255 & 0.002 & $0.002^{*}$ & 51.8
\end{tabular}

$p$-value for Mann-Whitney test (I) v. (III): $t+1=0.08 ; t+2=0.52 ; t+3=0.82$.

$p$-value for Mann-Whitney test (II) v. (III): $t+1=0.09 ; t+2=0.25 ; t+3=0.09$.

The table reports changes in control-adjusted operating performance relative to the disintegration year $t$. Statistical significance of mean values is assessed using a two-tailed $t$-test and bootstrapped standard errors. Statistical significance of median values is assessed using a two-tailed Wilcoxon matched-pairs signed-ranks test. \% Positive is the proportion of positive changes in controladjusted operating performance of the total number of events and statistical significance is assessed using a two-tailed sign test. ${ }^{* * *} p<0.01 ;{ }^{* *} p<0.05 ;{ }^{*} p<0.1$

pre-disintegration level. The results were comparable to those discussed for the full sample. The only difference is that large reductions in the degree of a firm's vertical integration appear to magnify the disintegration- related costs that occur in the first postdisintegration year.

Hypothesis 2, suggesting that performance improvements will be larger for more integrated firms that disintegrate, is not supported by the 
Table 4. The Effect of Vertical Disintegration on Operating Performance for "Common Support" Sample

Test of Hypothesis 1. All disintegrating firms

\begin{tabular}{lcrcl}
\hline Period & Obs. & Mean & Median & \% Positive \\
\hline $\mathrm{t}+1$ & 318 & -0.021 & $-0.006^{*}$ & 46.9 \\
$\mathrm{t}+2$ & 270 & 0.021 & 0.011 & 54.8 \\
$\mathrm{t}+3$ & 215 & 0.048 & $0.027^{* *}$ & $57.7^{* *}$ \\
\hline
\end{tabular}

Test of Hypothesis 2. The initial degree of vertical integration of the disintegration firms

\begin{tabular}{|c|c|c|c|c|c|c|c|c|}
\hline \multirow[b]{2}{*}{ Period } & \multicolumn{4}{|c|}{ (I) Highly-integrated disintegrating firms } & \multirow[b]{2}{*}{ Obs. } & \multicolumn{3}{|c|}{ (II) Other disintegrating firms } \\
\hline & Obs. & Mean & Median & $\%$ Positive & & Mean & Median & $\%$ Positive \\
\hline$t+1$ & 143 & $-0.045^{*}$ & $-0.012^{* *}$ & 43.4 & 175 & -0.001 & -0.001 & 49.7 \\
\hline$t+2$ & 124 & $-0.057^{* *}$ & 0.005 & 53.2 & 146 & $0.087^{* *}$ & 0.017 & 56.2 \\
\hline$t+3$ & 94 & 0.034 & 0.019 & 53.2 & 121 & 0.059 & $0.035^{* *}$ & $61.2^{* *}$ \\
\hline
\end{tabular}

$p$-value for Mann-Whitney test (I) v. (II): $t+1=0.34 ; t+2=0.10 ; t+3=0.44$.

Test of Hypothesis 3. Reactive versus proactive vertical disintegration

\begin{tabular}{|c|c|c|c|c|c|c|c|c|c|c|}
\hline \multirow[b]{2}{*}{ Period } & \multirow[b]{2}{*}{ Obs. } & \multicolumn{3}{|c|}{ (I) Reactive disintegration } & \multirow[b]{2}{*}{$\begin{array}{l}\text { Coef. of } \\
\text { Variation }\end{array}$} & \multirow[b]{2}{*}{ Obs. } & \multirow[b]{2}{*}{ Mean } & \multicolumn{3}{|c|}{ (II) Proactive disintegration } \\
\hline & & Mean & Median & $\%$ Positive & & & & Median & $\%$ Positive & $\begin{array}{l}\text { Coef. of } \\
\text { Variation }\end{array}$ \\
\hline $\mathrm{t}+1$ & 129 & $-0.059^{*}$ & $-0.013^{* *}$ & 43.4 & 6.4 & 189 & 0.005 & -0.004 & 49.2 & 77.2 \\
\hline $\mathrm{t}+2$ & 111 & 0.024 & 0.016 & $60.4^{* *}$ & 15.5 & 159 & 0.018 & 0.005 & 50.9 & 24.1 \\
\hline$t+3$ & 87 & $0.069^{* *}$ & $0.035^{* *}$ & $65.5^{* *}$ & 3.3 & 128 & 0.034 & 0.017 & 52.3 & 15.7 \\
\hline
\end{tabular}

$p$-value for Mann-Whitney test (I) v. (II): $t+1=0.11 ; t+2=0.16 ; t+3=0.02$.

$p$-value for variance equality test (I) v. (II): $t+1=0.62 ; t+2=0.03 ; t+3=0.00$.

Test of Hypothesis 4. Between-sector versus within-manufacturing vertical disintegration

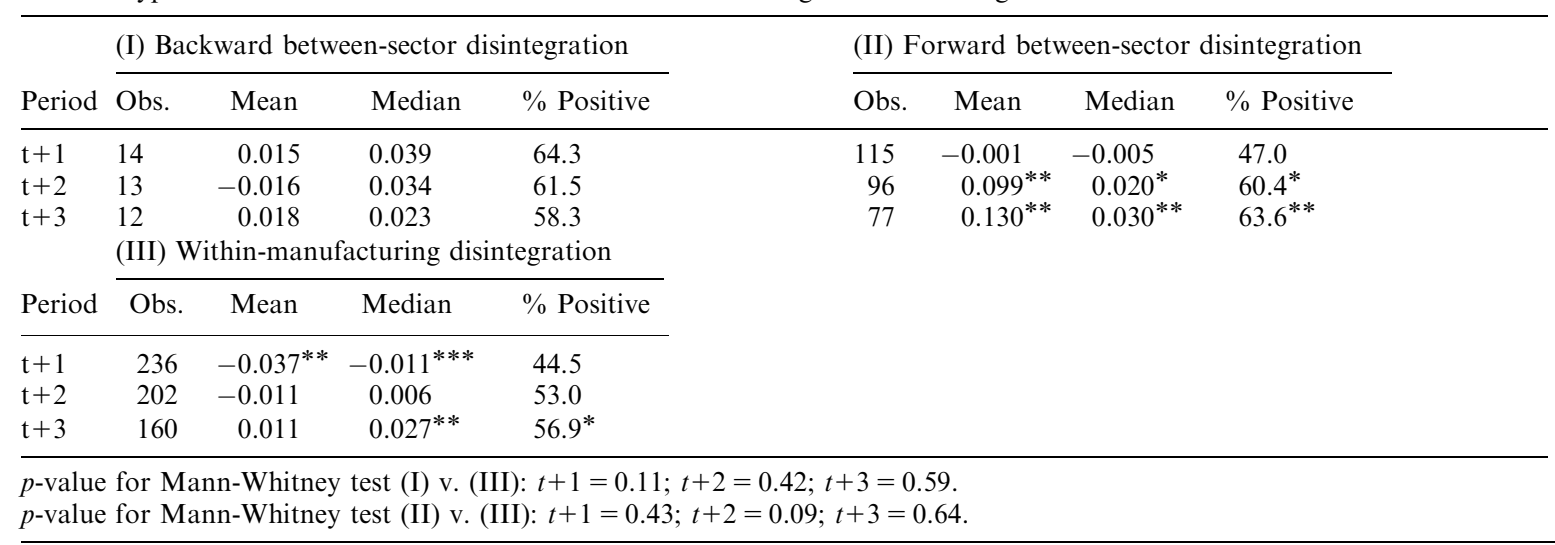

See notes to Table $3 .{ }^{* * *} p<0.01 ;{ }^{* *} p<0.05 ;{ }^{*} p<0.1$

results of the two tables. We also failed to find any statistically significant difference between the initially highly integrated firms and the other disintegrating firms, using a Mann-Whitney test for equality in the two distributions. Despite the finding from the regression analysis that integrated firms have a higher likelihood of disintegration, it appears that highly integrated firms cannot improve performance by simply restructuring to converge towards a hypothetical industry-wide 'optimal' level of vertical integration.

We then split the sample into reactive and proactive disintegrating events. In accordance with Hypothesis 3a, the results show that 
performance improvements are larger after reactive disintegration. In both tables, we obtain larger mean and median values and a larger percentage of positive effects for reactive disintegration compared with proactive disintegration in the second and third year. In the third year, the Mann-Whitney test rejects the hypothesis of the equality of the two distributions $(p<0.01$ in Table 3 and $p<0.05$ in Table 4). Three years after disintegration, about two in three reactively disintegrating firms - but only one in two proactively disintegrating firmsexperienced higher performance relative to the estimated counterfactual performance. Some evidence emerges supporting the complementary Hypothesis $3 \mathrm{~b}$ that the impact of reactive disintegration on performance will be subject to lower uncertainty. Tables 3 and 4 report the coefficient of variation (standard deviation as a percentage of the mean) of the estimated effect of disintegration on performance. The coefficient of variation for the performance effects of proactive disintegration is 1.8 and 3.1 times larger than the coefficient for reactive disintegration in the second and third post-disintegration years in Table 3. The corresponding values in Table 4 are 1.6 and 4.8. Performing tests on the equality of variances between the two groups of disintegrating firms we find a statistically significant difference in the second and third years for the samples of Tables $3(p<0.05$ and $p<0.01)$ and $4 \quad(p<0.05$ and $p<0.01)$.

Next, we split the sample into between-sector forward or backward disintegration and withinmanufacturing disintegration. ${ }^{6}$ We find no support for Hypothesis $4 \mathrm{a}$, which suggests that backward between-sector disintegration will result in a larger positive performance effect relative to withinmanufacturing disintegration. However, we find support for Hypothesis $4 \mathrm{~b}$, which suggests that forward between-sector disintegration will lead to a larger performance improvement relative to within-manufacturing disintegration. It appears that manufacturing firms that reduce their vertical scope by exiting from downstream services units experience a significantly larger boost in performance in the second and third post-disintegration years in terms of means, medians and proportions of positive effects. This finding is confirmed by a Mann-Whitney test, which rejects the hypothesis of the equality of the two distributions in the second and third postdisintegration year $(p<0.10$ at $t+3$ in Table 3 and at $t+2$ in Table 4). ${ }^{7}$ Another interesting finding is that within-manufacturing disintegration appears to be associated with a larger negative performance effect in the first post-disintegration year relative to both backward and forward between-sector disintegration (Mann-Whitney test $p<0.10$ in Table 3). The next section discusses and interprets these findings.

\section{DISCUSSION}

Despite the extant literature examining the relationship between levels of vertical integration and performance across firms, the question whether firms that disintegrate actually manage to improve their performance has received surprisingly little attention in the scholarly literature. In this paper we made the disintegrating firm the unit of our analysis and we investigated whether vertical disintegration improves operating performance. Because disintegration - like most types of organizational restructuring - is not a homogeneous phenomenon (Byerly et al., 2003), we also developed and tested predictions concerning the conditions under which disintegration is most likely to improve performance.

The results from the analysis confirm the prediction that vertical disintegration offers the potential for achieving improved operating performance. Three years after disintegration, some $54-58 \%$ of the disintegrating firms experienced higher operating performance relative to their estimated performance had they not disintegrated. However, the evidence suggests that firms that disintegrate go through a shortlived transitional period of performance decline in the first post-disintegration year. This finding supports the existence of significant disintegration costs, which is consistent with evidence from research on organizational change. Restructuring costs can arise from the disruption of networks of interdependent relationships with internal and external agents and of established mechanisms for allocating resources (Oster, 1982; Tushman and Romaelli, 1985). Costs can also arise from organizational redesign after eliminating functions, hierarchical levels and divisions of products (Cameron et al., 1993). Some of these expenses are likely to reflect 
investments in ICT and the development of the capabilities and culture that are required for effective inter-organizational cooperation (Brynjolfsson et al., 1994; Hitt et al., 1998).

We then carried out a contingency analysis. We found no evidence that the initially highly integrated disintegrating firms enjoyed larger performance improvements relative to the other disintegrating firms. Therefore, it seems that highly integrated firms cannot improve their performance by simply converging towards an industry-wide 'optimal' integration level. Instead, this finding is consistent with the view that the organizational structure is largely firm-specific and it needs to account for each firm's production experiences and organizational capabilities (Argyres, 1996; Holcomb and Hitt, 2007). Although the costs of vertical integration are likely to be more severe for highly integrated firms, for some firms these costs may still be low relative to the transaction costs that they face. There are two ways to justify this possibility. First, highly integrated firms may lack the necessary capability to adopt a less integrated organizational structure and the cooperative experience to select suitable partners and coordinate joint operations (Quinn, 2000; Holcomb and Hitt, 2007). Second, some firms may have built some superior internal capability for dealing effectively with an integrated organizational form, which partially alleviates the costs of vertical integration. For instance, Honda is renowned in the automotive industry for its sophisticated inventory management and internal processes (Maloney, 2000). The finding about the initially highly integrated firms implies that firms should resist the uncritical adoption of organizational models that become management fads and which are frequently spread across clusters of companies (DiMaggio and Powell, 1983). If, for some reason, managers do attempt to redesign their vertical scope and adopt a less integrated structure, they should first build the necessary organizational capabilities.

In relation to the timing of vertical disintegration, it turns out that performance improvements are relatively larger, subject to less uncertainty and more frequent after reactive disintegration. The finding that performance improvements are larger in reactive disintegration is consistent with evidence that, in competitive markets, inappropriately aligned organizational arrangements cannot persist indefinitely, as they impose significant performance penalties (Masten, 1993; Mayer and Nickerson, 2005; Geyskens et al., 2006). It is also consistent with evidence about the existence of significant performance gains after reactive downsizing (e.g. Espahbodi et al., 2000). The finding about the lower uncertainty of performance gains from reactive disintegration accords with evidence from work on organizational attributes and performance that 'standards-based strategists', whose technologies conform to publicly available specifications, perform better in the short- to medium-term compared with 'proprietary strategists' who use internally developed, firm-specific technologies (Schoonhaven et al., 1990; Henderson, 1999). Our findings suggest that managers who adopt exploratory strategies that are associated with the vertical scope of the firm should be aware that such strategies are high risk and bear fruit, if any, in the longer term.

In relation to the direction of vertical disintegration, we find that exiting from downstream services units leads to higher performance improvements relative to withinmanufacturing disintegration. This finding is consistent with the argument that the potential for performance improvement is larger for forward between-sector disintegration because it allows the elimination of inefficiencies arising from undertaking tasks that require fundamentally different capabilities from those that have been built around the centre of gravity of the firm (Galbraith, 1983). Inspection of our data reveals that a large proportion (about 20\%) of forward between-sector disintegration involved firms operating in SIC 20: Food and kindred products (e.g. Diageo, Unilever, Cadbury Schweppes). Among these disintegration events, about half $(46 \%)$ of the divested units belong to SIC 58: Eating and drinking places. Although the failure to find a larger performance improvement for manufacturing firms exiting from raw materials relative to within-manufacturing disintegration may be due to the small samples, it may also reflect a weak strategic position of manufacturing firms in relation to independent suppliers of raw materials (Porter, 1979, 2008). In such cases, managers may be better off adopting tapered integration (Harrigan, 1984). Recent evidence suggests that the concurrent internal and external sourcing of inputs is associated with higher performance (Rothaermel et al., 2006; 
Parmigiani, 2007). Another interesting finding is that within-manufacturing disintegration appears to be associated with a larger negative performance effect in the first post-disintegration year compared with both backward and forward between-sector disintegration. This is likely to reflect the relatively greater difficulties in disentangling closely integrated steps in the production chain. A typical example of the requirements imposed by interconnections among product component interfaces is the automotive industry, where disintegration and outsourcing also require redesigning the product architecture (Sako, 2003, 2005).

At a methodological level, our study has highlighted the importance of addressing the problem of the endogeneity of strategic decisions when the aim is to estimate their causal effect on outcome variables. Given that the problem of the endogeneity of strategic decisions is relevant to many of the organizational phenomena that have been investigated in empirical management research (Hamilton and Nickerson, 2003; Villalonga, 2004; Danzon et al., 2007), we hope that our study has demonstrated the value of the propensity score matching method.

As is the case with most empirical work, we recognize limitations in our study, which also suggest promising areas of future research. Using accounting data, which are inherently backward looking in nature, to proxy for firm performance limits our ability to assess the longer-term consequences of disintegration on performance. We suspect that this factor may underlie our finding about the rather neutral effect of proactive disintegration on performance. It is possible that performance after proactive disintegration, which is often part of a broader organizational redesign with long-term strategic objectives, can best be understood within longer time frames (Montgomery et al., 1984; Montgomery and Thomas, 1988). Further research using forwardlooking stock market data to proxy for corporate performance is likely to overcome this limitation. Another limitation of this study arises from the level of analysis that was adopted. Our research design allowed us to test the validity of the claim that reducing the vertical scope of the firm can improve performance for a large sample of firms. However, we were not able to account and control for subtle qualitative differences in product architectures and production processes, which might limit managerial choice of an appropriate organizational design (Schilling, 2000; Brusoni et al., 2001; Sako, 2003). Further work on the basis of a carefully selected small sample of firms that would allow the collection of information on fine-grained qualitative characteristics of products and processes would be an interesting extension of this paper.

\section{Acknowledgements}

The author gratefully acknowledges financial support from the ESRC/EPSRC under the AIM initiative. He would like to thank the MDE anonymous referees, Mari Sako, Howard Gospel, Susan Helper, P. Devereaux Jennings, Jack Nickerson, Thomas Powell and the seminar and conference participants at the Academy of Management Meeting, the Strategic Management Society Conference, University of Oxford and SDA Bocconi.

\section{NOTES}

1. Because Datastream's coverage of the costs of bought-in materials, components and services is very poor, we approximate this expression by the sum of earnings before interest, taxation, depreciation and amortization (EBITDA) and employee costs (see The Value Added Scoreboard, dti, 2004).

2. Two events initiated by British American Tobacco that took place in 1996 and 1997 fall from the sample because there is no control firm in the same 2-digit industry class (Tobacco Products) with the required data.

3. Although in theory restructuring charges should appear in extraordinary items (since they are unusual in nature, infrequent in occurrence and material in impact), in which case operating profit figures should not be affected, in practice firms sometimes show restructuring charges as part of operating expenses.

4. For the calculation of the percentage effect, the median estimated effect on performance is divided by the sum of the actual median performance of the sample firms in the divestiture year and the median change in performance of the matched control firms (e.g. at $t+1$ we have $-0.006 /(0.147+(-0.0025)) \times$ $100 \approx-4 \%)$.

5. The main reason for the fall in sample sizes is that data on performance are available for less than 3 years for disintegration events taking place after 2001. Another reason is that firms might die due to acquisition or liquidation.

6. Because a firm might be active in multiple divestitures in a given year, some events are counted twice if the industrial relationship differs between the disintegrating firm and each of the divested units. 
7. We checked whether the more positive performance effect of forward between-sector disintegration should be attributed to a significantly higher concentration of reactive disintegration events but found no evidence of this.

\section{REFERENCES}

Abramovsky L, Griffith R. 2006. Outsourcing and offshoring of business services: how important is ICT? Journal of the European Economic Association 4: 594-601.

Argyres N. 1996. Evidence on the role of firm capabilities in vertical integration decisions. Strategic Management Journal 17: 129-151.

Atiase RK, Platt DE, Tse SY. 2004. Operational restructuring charges and post-restructuring performance. Contemporary Accounting Research 21: 493-522.

Barber BM, Lyon JD. 1996. Detecting abnormal operating performance: the empirical power and specification of test-statistics. Journal of Financial Economics 41: 359-399.

Barney J. 1991. Firm resources and sustained competitive advantage. Journal of Management 17: 99-120.

Bettis RA, Bradley SP, Hamel G. 1992. Outsourcing and industrial decline. The Executive 6: 7-23.

Bowman EH, Singh H, Useem M, Bhadury R. 1999. When does restructuring improve economic performance? California Management Review 41: 33-54.

Brusoni S, Prencipe A, Pavitt K. 2001. Knowledge specialization, organizational coupling, and the boundaries of the firm: why do firms know more than they make? Administrative Science Quarterly 46: 597-621.

Brynjolfsson E, Malone TW, Gurbaxani V, Kambil A. 1994. Does information technology lead to smaller firms? Management Science 40: 1628-1644.

Byerly RT, Lamont BT, Keasler T. 2003. Business portfolio restructuring, prior diversification posture and investor reactions. Managerial and Decision Economics 24: 535-548.

Cameron KS, Freeman SJ, Mishra AK. 1993. Downsizing and redesigning organizations. In Organizational Change and Redesign: Ideas and Insights for Improving Performance, Huber GP, Glick WH (eds). Oxford University Press: New York; 19-65.

Cho M-H, Cohen MA. 1997. The economic causes and consequences of corporate divestiture. Managerial and Decision Economics 18: 367-374.

Christensen CM, Verlinden M, Westerman G. 2002. Disruption, disintegration and the dissipation of differentiability. Industrial and Corporate Change 11: 955-993.

Coase RH. 1937. The nature of the firm. Economica 4: 386-405.
Daley L, Mehrotra V, Sivakumar R. 1997. Corporate focus and value creation. Evidence from spinoffs. Journal of Financial Economics 45: 257-281.

Danzon PM, Epstein A, Nicholson S. 2007. Mergers and acquisitions in the pharmaceutical and biotech industries. Managerial \& Decision Economics 28: 307-328.

D'Aveni RA, Ilinitch AY. 1992. Complex patterns of vertical integration in the forest products industry: systematic and bankruptcy. Academy of Management Journal 35: 596-625.

D'Aveni RA, Ravenscraft DJ. 1994. Economies of integration versus bureaucracy costs: does vertical integration improve performance? Academy of Management Journal 37: 1167-1206.

Davis R, Duhaime IM. 1992. Diversification, vertical integration and industry analysis: new perspectives and measurement. Strategic Management Journal 13: 511-524.

Denis D, Shome DK. 2005. An empirical investigation of corporate asset downsizing. Journal of Corporate Finance 11: 427-448.

Department of Trade and Industry. 2004. The Value Added Scoreboard. DTI: UK.

Dierickx I, Cool K. 1989. Asset stock accumulation and sustainability of competitive advantage. Management Science 35: 1504-1511.

DiMaggio PJ, Powell WW. 1983. The iron cage revisited: institutional isomorphism and collective rationality in organizational fields. American Sociological Review 48: 147-160.

Eisenhardt KM, Brown SL. 1999. Patching. (cover story). Harvard Business Review 77: 72-82.

Eisenhardt KM, Martin JA. 2000. Dynamic capabilities: what are they? Strategic Management Journal 21: 1105-1121.

Engardio P, Arndt M, Foust D. 2006. The future of outsourcing: how it's transforming whole industries and changing the way we work. BusinessWeek January 30 .

Espahbodi R, John TA, Vasudevan G. 2000. The effects of downsizing on operating performance. Review of Quarterly Finance and Accounting 15: 107-126.

Finkelstein S, Hambrick DC. 1996. Strategic Leadership: Top Executives and Their Effects on Organizations. West: St. Paul.

Galbraith JR. 1983. Strategy and organization planning. Human Resource Management 22: 63-77.

Geyskens I, Steenkamp J-BEM, Kumar N. 2006. Make, buy, or ally: a transaction cost theory meta-analysis. Academy of Management Journal 49: 519-543.

Gilley KM, Rasheed A. 2000. Making more by doing less: an analysis of outsourcing and its effects on firm performance. Journal of Management 26: 763-790.

Hamel G, Prahalad CK. 1994. Competing for the future. Harvard Business School Press: Boston, MA.

Hamilton BH, Nickerson JA. 2003. Correcting for endogeneity in strategic management research. Strategic Organization 1: 51-78.

Hannan MT, Freeman J. 1984. Structural inertia and organizational change. American Sociological Review 49: 149-164. 
Harrigan KR. 1984. Formulating vertical integration strategies. Academy of Management Review 9: 638-652.

Harrigan KR. 1985. Strategies for intrafirm transfers and outside sourcing. Academy of Management Journal 28: 914-925.

Haynes M, Thompson S, Wright M. 2002. The impact of divestment on firm performance: empirical evidence from a panel of UK companies. Journal of Industrial Economics 50: 173-196.

Haynes M, Thomson S, Wright M. 2003. The determinants of corporate divestment: evidence from a panel of UK firms. Journal of Economic Behavior and Organization 52: 147-166.

Helfat CE, Peteraf MA. 2003. The dynamic resource-based view: capability lifecycles. Strategic Management Journal 24: 997-1010.

Henderson AD. 1999. Firm strategy and age dependence: a contingent view of the liabilities of newness, adolescence, and obsolescence. Administrative Science Quarterly 44: 281-314.

Hitt M, Hoskisson R, Johnson RA, Moesel DD. 1996. The market for corporate control and firm innovation. Academy of Management Journal 39: 1084-1119.

Hitt MA, Keats BW, DeMarie SM. 1998. Navigating in the new competitive landscape: building strategic flexibility and competitive advantage in the $21 \mathrm{st}$ century. Academy of Management Executive 12: $22-42$.

Holcomb TR, Hitt MA. 2007. Toward a model of strategic outsourcing. Journal of Operations Management 25: 464-481.

Jacobides MG. 2005. Industry change through vertical disintegration: how and why markets emerged in mortgage banking. Academy of Management Journal 48: 465-498.

Jacobides MG, Winter SG. 2005. The co-evolution of capabilities and transaction costs: explaining the institutional structure of production. Strategic Management Journal 26: 395-413.

John K, Ofek E. 1995. Asset sales and increase in focus. Journal of Financial Economics 37: 105-126.

Johnson G. 1990. Managing strategic change; the role of symbolic action. British Journal of Management 1: $183-200$.

Jones MT. 2002. Globalization and organizational restructuring: a strategic perspective. Thunderbird International Business Review 44: 325-351.

Kogut B, Zander U. 1992. Knowledge of the firm, combinative capabilities, and the replication of technology. Organization Science 3: 383-397.

Lang L, Poulsen A, Stulz R. 1995. Asset sales, firm performance, and the agency costs of managerial discretion. Journal of Financial Economics 37: 3-37.

Lee PM. 1997. A comparative analysis of layoff announcements and stock price reactions in the United States and Japan. Strategic Management Journal 18: 879-894.

Leiblein MJ. 2003. The choice of organizational governance form and performance: predictions from transaction cost, resource-based, and real options theories. Journal of Management 29: 937-961.
Love EG, Nohria N. 2005. Reducing slack: the performance consequences of downsizing by large industrial firms. Strategic Management Journal 26: 1087-1108.

Maddigan RJ, Zaima JK. 1985. The profitability of vertical integration. Managerial and Decision Economics 6: 178-179.

Mahoney JT. 1992. The choice of organizational form: vertical financial ownership versus other methods of vertical integration. Strategic Management Journal 13: 559-584.

Maloney D. 2000. The driving force behind Honda. Modern Materials Handling 73.

Markides CC. 1995. Causes and consequences of corporate restructuring. In Strategic Renaissance and Business Transformation, Thomas H, O'Neal D, Kelly J (eds). Wiley: New York.

Masten SE. 1993. Transaction costs, mistakes, and performance: assessing the importance of governance. Managerial \& Decision Economics 14: 119-129.

Mayer KJ, Nickerson JA. 2005. Antecedents and performance implications of contracting for knowledge workers: evidence from information technology services. Organization Science 16: 225-242.

Mitchell LM, Mulherin JH. 1996. The impact of industry shocks on takeover and restructuring activity. Journal of Financial Economics 41: 193-229.

Montgomery CA, Thomas AR. 1988. Divestment: motives and gains. Strategic Management Journal 9: 93-97.

Montgomery CA, Thomas AR, Kamath R. 1984. Divestiture, market valuation, and strategy. Academy of Management Journal 27: 830-840.

Oster S. 1982. Intraindustry structure and the ease of strategic change. Review of Economics \& Statistics 64 : 376-383.

Parmigiani A. 2007. Why do firms both make and buy? An investigation of concurrent sourcing. Strategic Management Journal 28: 285-311.

Penrose ET. 1959. The theory of the growth of the firm. Wiley: New York.

Peyrefitte J, Golden PA. 2004. Vertical integration and performance in the United States computer hardware industry. International Journal of Management 21: 246-251.

Porter ME. 1979. How competitive forces shape strategy. Harvard Business Review 57: 137-145.

Porter ME. 2008. The five competitive forces that shape strategy. Harvard Business Review 86: 78-93.

Prahalad CK, Bettis RA. 1986. The dominant logic: a new linkage between diversity and performance. Strategic Management Journal 7: 485-501.

Prahalad CK, Hamel G. 1990. The core competence of the corporation. Harvard Business Review 68: 79-93.

Quinn JB. 1992. Intelligent Enterprise: A Knowledge and Service Based Paradigm for Industry. Free Press: New York.

Quinn JB. 2000. Outsourcing innovations: the new engine of growth. Sloan Management Review 41: $13-28$. 
Quinn JB, Hilmer FG. 1994. Strategic outsourcing. Sloan Management Review 35: 43-55.

Robins JA. 1993. Organization as strategy: restructuring production in the film industry. Strategic Management Journal 14: 103-118.

Rosenbaum PR, Rubin DB. 1983. The central role of the propensity score in observational studies for causal effects. Biometrika 70: 41-55.

Rosenbaum PR, Rubin DB. 1984. Reducing bias in observational studies using subclassification on the propensity score. Journal of the American Statistical Association 79: 516-524.

Rosenbaum PR, Rubin DB. 1985. Constructing a control group using multivariate matched sampling models that incorporate the propensity score. American Statistician 39: 33-38.

Rothaermel FT, Hitt MA, Lloyd AJ. 2006. Balancing vertical integration and strategic outsourcing: effects on product portfolio, product success, and firm performance. Strategic Management Journal 27: 1033-1056.

Sako M. 2003. Mo'dularity and outsourcing: the nature of co-evolution of product architecture and organisation architecture in the global automotive industry. In The Business of Systems Integration, Prencipe A, Davies A, Hobday M (eds). Oxford University Press: Oxford; 229-253.

Sako M. 2005. Outsourcing and offshoring: key trends and issues, Background paper prepared for the Emerging Markets Forum, September.

Schilling MA. 2000. Toward a general modular systems theory and its application to interfirm product modularity. Academy of Management Review 25: 312-334.

Schoonhoven CB, Eisenhardt KM, Lyman K. 1990. Speeding products to market: waiting time to first product introduction in new firms. Administrative Science Quarterly 35: 177-207.

Shimizu K, Hitt MA. 2004. Strategic flexibility: organizational preparedness to reverse ineffective strategic decisions. Academy of Management Executive 18: 44-59.

Sianesi B. 2001. Propensity score matching. In United Kingdom Stata Users' Group, VII Meeting, London.

Sorenson O. 2003. Interdependence and adaptability: organizational learning and the long-term effect of integration. Management Science 49: 446-463.

Stigler GJ. 1951. The division of labour is limited by the extent of the market. Journal of Political Economy 59: 185-193.

Teece DJ. 1993. Profiting from technological innovation: implications for integration, collaboration, licensing and public policy. Research Policy 22: 112-113.

Teece D, Pisano GP, Shuen A. 1997. Dynamic capabilities and strategic management. Strategic Management Journal 18: 509-533.

Todd P. 1999. A practical guide to implementing matching estimators. Paper prepared for IADB Meeting in Santiago, Chile. October 1999.

Tushman ML, Romaelli E. 1985. Organizational evolution: a metamorphosis model of convergence and reorganization. In Research in Organizational Behaviour, Staw MB, Cummings LL (eds). JAI Press: Greenwich, CT.

Villalonga B. 2004. Does diversification cause the 'diversification discount'? Financial Management 33: $5-27$.

Wernerfelt B. 1984. A resource-based view of the firm. Strategic Management Journal 5: 171-180.

Williamson OE. 1975. Markets and Hierarchies: Analysis and Antitrust Implications. Free Press: New York.

Williamson OE. 1979. Transaction-cost economics: the governance of contractual relations. Journal of Law and Economics 22: 233-261.

Williamson OE. 1981. The economics of organization: the transaction cost approach. American Journal of Sociology 87: 548-577. 